https://doi.org/10.30681/real.v14.4959

\title{
AVANÇOS E RECUOS DA MULHER NIGERIANA EM MEIO SOL AMARELO, DE CHIMAMANDA NGOZI ADICHIE
}

\author{
Maicom Diulho Dino SCARIOT (UFAM) ${ }^{1}$ \\ Elis Regina Fernandes ALVES (UFAM) ${ }^{2}$
}

RESUMO: Esta pesquisa analisa o romance Meio Sol Amarelo (2006), de Chimamanda Ngozi Adichie, tendo como base a teoria literária feminista, com foco nas personagens Olanna e Kainene. Para esta investigação, foram utilizados autoras como Beauvoir (1967;1970), Bourdieu (2012), Perrot (2007), Woolf (1990), e outras. O objetivo central do estudo foi analisar como as personagens femininas do romance cedem às imposições patriarcais ou conseguem romper com elas, impondo-se e exigindo a igualdade entre os gêneros. Olanna apresenta-se mais passiva às imposições patriarcais, porque ela se encaixa e segue os padrões de mulher ideal da época, aceitando a traição do marido, ansiando pela maternidade. Kainene consegue uma libertação superior, mas sofre com as condições em que isso ocorre, já que as conquistas estão atreladas à sua condição de mulher feia. As irmãs gêmeas não idênticas, Olanna e Kainene, enfrentam de maneira distinta as imposições patriarcais, pois possuem padrões estéticos distintos que as diferenciam socialmente. A análise revela que a classe social elevada das imãs é de suma importância para as conquistas que elas usufruem, pois possuem acesso à boa educação, o que lhes permite romper com as imposições sociais familiares.

Palavras-chave: feminismo; Crítica literária feminista; Meio sol amarelo.

ABSTRACT: This research analyzes Chimamanda Ngozi Adichie's novel Half of a Yellow Sun (2006), basing on feminist literary theory and focusing on the characters Olanna and Kainene. For this investigation, it has been used authors like Beauvoir (1967;1970), Bourdieu (2012), Perrot (2007), Woolf (1990), and others. The main objective was to analyze how the female characters in this novel submitted to the patriarchal impositions or break up with it, stablishing themselves to demand equality of genders. Olanna is more submissive to the patriarchal system, because she fits the model of the idealized woman of that time. She accepts her husband's betrayal, desiring motherhood. Kainene achieves more freedom, but she suffers to the conditions imposed for that, as these conquests are tied to her ugly woman's condition. The non-identical twin sisters, Olanna and Kainene, face the patriarchal impositions in a distinct way, because they have different aesthetic patterns that discriminate them in society. The analysis reveals that the sister's high social class is very important to the achievements they achieve, because they receive a good education, which allows the sisters to break up with their family social impositions.

Keywords: feminism; Feminist Literary Criticism; Half of a Yellow Sun.

\section{Introdução}

O equívoco comum a respeito do termo feminismo envolve a deturpação de seu sentido: a de que o feminismo seria o oposto ao machismo. Porém, o entendimento do que seja,

\footnotetext{
${ }^{1}$ Discente do curso de Letras- Português e inglês da UFAM- Universidade Federal do Amazonas, no IEAAInstituto de Educação, Agricultura e Ambiente de Humaitá- Amazonas. E-mail: maicom.scariot2m@gmail.com

${ }^{2}$ Docente do curso de Letras UFAM- Universidade Federal do Amazonas, no IEAA- Instituto de Educação, Agricultura e Ambiente de Humaitá- Amazonas. Doutora em Letras pela UNESP- São José do Rio Preto- IBILCE. E-mail: elisregi@ufam.edu.br
} 
de fato, o feminismo deve envolver o estudo sobre as lutas feministas ao longo dos séculos, jamais em busca da diferença em relação aos direitos dos homens, mas da igualdade. Neste sentido, as mulheres, em diferentes períodos históricos, avançaram e recuaram em relação às conquistas por essa igualdade. Isso se deu pelo esforço da mulher tentar sair de uma situação de inferioridade e, ao mesmo tempo, o homem utilizar-se de sua superioridade construída para mantê-la numa posição inferior em relação aos direitos civis e políticos.

No mundo contemporâneo, após a sistematização de uma crítica literária feminista, consequência dos movimentos feministas, a literatura passou a ser vista sob um novo olhar. Como a literatura, em seu aspecto verossímil, apresenta uma organização social que representa a percepção de realidade de um povo, certos padrões femininos apresentados na literatura estão diretamente ligados à sociedade patriarcal. Assim, a representação de uma mulher subserviente foi tida como natural durante muito tempo, mesmo as mulheres escritoras reproduziam esses padrões femininos. Então, a crítica literária feminista surge para que haja uma compreensão acerca da representação ficcional da mulher em uma sociedade patriarcal e, dessa maneira, entendermos como a sociedade se organiza para que seja possível a criação de determinada imagem feminina.

A literatura, com seus aspectos simbólicos, constitui-se em uma área muito importante para se discutir a situação da mulher na sociedade, levando em consideração os aspectos sociais que a escrita literária, apoiada em uma teoria, elucidam. À vista disso, esta pesquisa, de cunho bibliográfico, busca analisar como as personagens femininas do romance Meio sol amarelo, de Chimamanda Ngozi Adichie, cedem às imposições patriarcais ou conseguem romper com elas, impondo-se e exigindo a igualdade entre os gêneros. Como essa obra é baseada em fatos históricos, e retrata um período especifico da Nigéria, a partir dos anos 60, entendemos que o romance apresenta aspectos sociais e culturais de uma época distinta que relegam à mulher a condição de subalternidade. Assim, discutindo tais temáticas com a análise das personagens femininas do romance, pressupõe-se que isso ajudará a materializar as causas do recuo e do avanço dessas personagens no patriarcado.

\section{O papel histórico da mulher}

Ao longo de muitos séculos, a mulher foi inferiorizada em relação aos homens, e os direitos que hoje possui levaram muito tempo para serem conquistados. A sociedade, cujo poder era exercido unicamente pelos homens, a colocava à margem, numa posição de extrema 
irrelevância social, tendo sua condição de existência atribuída aos serviços que eram definidos para seu sexo. Assim, diminuída nos mais diversos âmbitos sociais, familiares e políticos, ela não tem, durante muito tempo, outra função a não ser a subserviência ao sexo masculino.

$\mathrm{Na}$ segunda metade do século XVIII, quando há um novo sistema econômico desenvolvendo-se (capitalismo) e grande mudança das estruturas sociais vigentes, com novos ideais que proporcionaram uma nova organização social a partir da participação populacional na esfera política, temos uma mulher que, apesar da participação nos movimentos políticos ao lado do homem, como ocorreu durante a Revolução Francesa, não usufrui das conquistas políticas adquiridas (ALVES e PITANGUY, 1985; MICHEL, 1982), pois os movimentos revolucionários sempre foram comandados por homens. Segundo Beauvoir (1970, p. 141): "Poder-se-ia imaginar que a Revolução transformasse o destino feminino. Não foi o que aconteceu. A revolução burguesa mostrou-se respeitosa das instituições e dos valores burgueses; foi feita quase exclusivamente pelos homens". E é nesse contexto de mudanças e preservação de valores burgueses que temos a permanência da mulher no lugar de subalternidade definido séculos atrás. A condição social da mulher era naturalizada. E as próprias mulheres perpetuavam tal sistema de dominação masculina, pois, segundo Bourdieu (2012, p. 22):

Quando os dominados aplicam àquilo que os domina esquemas que são produto da dominação ou, em outros termos, quando seus pensamentos e suas percepções estão estruturados de conformidade com as estruturas mesmas da relação da dominação que lhes é imposta, seus atos de conhecimento são, inevitavelmente, atos de reconhecimento, de submissão. (grifo do autor).

Desta forma, a naturalização da mulher com tais papeis definidos ocorre, pois a mulher já nasce nesse sistema ideológico de dominação, tendo uma ideia de naturalização das posições sociais que ocupam os sexos. Mas, para isso, viviam sujeitas a mecanismos de dominação masculina impostos durante sua vida, como a religião, que exerce poder sobre as mulheres: “[...] as grandes religiões monoteístas fizeram da diferença dos sexos e da desigualdade de valor entre eles um de seus fundamentos. A hierarquia do masculino e do feminino lhes parece da ordem de uma Natureza criada por Deus.” (PERROT, 2007, p. 83-84). Levando em consideração esse modelo religioso apresentado, percebemos que as sociedades que têm em suas estruturas uma religião monoteísta, têm, também, a crença de que a inferiorização da mulher é algo natural, já que foi criada por uma divindade. Dessa forma, a religião se torna um argumento para que os homens justifiquem o patriarcado como sendo de uma ordem divina. 
No casamento, que naquela época era uma obrigação social imposta a mulher, não havia simetria na relação, ao homem era aceitável socialmente que tivesse relações sexuais com prostitutas, desde que respeitasse o espaço da sua mulher legítima. Outro ponto são as necessidades do casamento para ambos: para a mulher, o casamento era o único meio de integrar-se à sociedade e, devido a isso, a mulher que não conseguia se casar tornava-se um ser socialmente desprezível (BEAUVOIR, 1967).

Em relação à educação, a mulher possui, em 1790, acesso a um ensino voltado somente para as prendas domésticas: "O currículo das meninas enfatizava o aprendizado das prendas domésticas e sua escolarização não as preparava para o ensino superior, que, aliás, sequer lhes era acessível." (ALVES E PITANGUY, 1985, p. 28). O ensino era diferenciado para que a mulher desde pequena entendesse qual era seu papel social. Não tinha o direito a adentrar ao ensino superior, pois entendia-se que a mulher não precisa ter uma profissão, pois seria sustentada pelo marido. (BEAUVOIR, 1967). Todavia, ainda no século XVIII, há o início tímido de um feminismo organizado, em que mulheres começam a perceber a necessidade de reivindicar diretos para seu gênero, com Mary Wollstonecraft, uma das maiores representantes da época, o fez ao publicar Reivindicação dos direitos da mulher, em 1792. No século XIX esse movimento virá com mais intensidade, o que possibilitará algumas conquistas. Porém, essas conquistas advêm de muita luta em uma sociedade em que os homens exercem o poder máximo, além dos ideais burgueses preconizarem uma estrutura que mantinha a subalternidade feminina.

Com a modernidade, no século XIX, as relações entre homens e mulheres, como o casamento, se sustentam com outros valores: "Os termos da troca se tornam mais complexos: a beleza, a atração física entram em cena. Um homem de posses pode desejar uma jovem pobre, mas bela. Os encantos femininos constituem um capital.” (PERROT, 2007, p. 47). Se antes a sociedade via o amor do casal como um fator relevante para as relações conjugais, agora, entra, também, o fator estético e econômico. A condição social do homem e o corpo feminino tornamse relevantes nas relações.

Este século, de um modo geral, é um período de organização social para que as mulheres que despertaram um início de reivindicações no século anterior, não venham interferir novamente na ordem social, como podemos constatar com o cenário histórico da Inglaterra:

Na Inglaterra, a condição social da mulher na Era Vitoriana (1832-1901) foi tenazmente marcada por diversos tipos de discriminações, justificadas como argumento da suposta inferioridade intelectual das mulheres, cujo cérebro pesaria 2 libras e 11 onças, contra as 3 libras e meia do cérebro masculino. 
Resulta disso que a mulher que tentasse usar seu intelecto, ao invés de explorar sua delicadeza, compreensão, submissão, afeição ao lar, inocência e ausência de ambição, estaria violando a ordem natural das coisas, bem como a tradição religiosa (ZOLIN, 2003a, p. 184).

Nesse período é imposta a ideia de uma suposta inferioridade feminina com bases em uma pseudociência. E, assim, se instaura com muita força a crença de que a mulher deve se ocupar-se com os afazeres domésticos no mundo interno, enquanto o homem cuida de questões políticas no mundo externo, pois este possuía inteligência, de acordo com este discurso pseudocientífico. Assim, tentava-se mantê-la longe de qualquer possibilidade de tentar modificar sua condição. E essa condição era construída culturalmente, pelo fato de o homem se apropriar dos meios de transformação social como a política e a ciência, por exemplo. Segundo Bourdieu (2012, p. 33): “A força particular da sociodicéia masculina lhe vem do fato de ela acumular e condensar duas operações: ela legitima uma relação de dominação inscrevendo-a em uma natureza biológica que é, por sua vez, ela própria uma construção social naturalizada". Desta forma a sociedade se organiza, o homem atesta sua superioridade através de uma natureza biológica que vem de uma construção social. E a mulher, sendo o ser mais frágil nessa linha de raciocínio, é moldada para aceitar sua inferioridade. Por isso, o acesso à educação foi uma das mais importantes conquistas para a mulher:

$\mathrm{O}$ acesso da mulher ao ensino superior, à igualdade de possibilidades em relação ao homem, constituiu um dos principais objectivos das feministas [...] $\hat{E}$ muito provável que a revolução sexual tivesse tido um ímpeto muito menor[...], se um número cada vez maior de mulheres não tivesse beneficiado do ensino superior, que foi uma das mais importantes realizações desse período (MILLETT, 1970, p. 30).

A educação teve um papel fundamental para a mulher conseguisse, enfim, obter espaços sociais que nunca tivera ao longo da história. E um destes espaços era o da escrita, também restrita à maioria das mulheres, como veremos a seguir.

\section{Literatura e feminismo}

A literatura, em relação à luta feminista, tem um papel muito importante, já que a escrita, durante muito tempo, era algo negado às mulheres. Todavia, através de muita resistência a mulher começou a ser reconhecida no ramo literário, constituindo, assim, uma tradição literária e tendo um público leitor que lia cada vez mais obras de autoria feminina, o que 
garantiu que elas pudessem trabalhar como escritoras e, tendo mais espaço para expor suas ideias, pudessem denunciar a opressão sofrida através da literatura.

A partir de 1860, o mercado literário se expandiu muito devido às ocorrências dos movimentos feministas, resultado da ascensão de uma mulher que luta por direitos e não se esconde atrás de pseudônimos masculinos. Essa nova sociedade possibilitou o surgimento de romances sensacionalistas que subvertem a tradição literária, e conseguem quebrar o monopólio de publicações masculinas, pois as mulheres, em um movimento de ascensão social, sentem a necessidade de produzir e consumir obras mais ousadas. São expressadas, nessas obras, as emoções reprimidas de mulheres e isso satisfazia as fantasias de protesto e fuga daquela condição de subjugadas contra a qual estavam resistindo (SHOWALTER, 2014).

Com a luta pelo sufrágio feminino, que se fortalece no fim do século XIX e início do XX, a possibilidade de abertura para direitos sociais e a conscientização da desigualdade de direitos entre os gêneros, as mulheres sentiram necessidade, também, de se organizar na produção de uma literatura voltada para a psicologia feminina, com a intenção de fazer as mulheres de classe média conscientizarem-se da opressão que sofriam (SHOWALTER, 2014). É nessa conjuntura que surge Virgínia Woolf (1882-1941), que pode ser considerada uma das principais escritoras do século $\mathrm{XX}$, dada sua grande contribuição ao movimento feminista ocidental. Fazendo uso do fluxo de consciência, ela buscava revelar a realidade interna das personagens femininas (BONNICI, 2007) e conseguia conscientizar leitores sobre a opressão sofrida pela mulher, aproximando-os dos sentimentos e visão das personagens femininas.

Woolf também foi uma importante crítica literária. No livro Um teto todo seu, de 1929, ela discute o papel da mulher na literatura, levando em consideração o meio social em que ela se encontra, sendo muito mais difícil para uma mulher ter algum sucesso na literatura por conta da educação precária recebida e de todo um conjunto social opressor. Só o talento, para a mulher, não bastava para se destacar no ramo literário. Cita como exemplo Wiliam Shakespeare que, segundo ela, não teria êxito na literatura se tivesse nascido em outro gênero. A mulher precisaria, então, de um "teto todo seu", que seria um lugar onde ela pudesse escrever tranquilamente, sem interrupções, e ser remunerada pelo seu trabalho, para que não dependesse de ninguém.

No século XX surge, também, Simone de Beauvoir (1908-1986), filósofa existencialista que foi a principal responsável por consolidar uma teoria feminista. Em seu livro O segundo Sexo: A Experiência Vivida, de 1949, Beauvoir faz uma explanação de como a 
mulher, no século XX, mesmo tendo certa liberdade econômica, não possui a mesma liberdade que um homem:

\begin{abstract}
A mulher que se liberta economicamente do homem nem por isso alcança uma situação moral, social e psicológica idêntica à dele. A maneira por que se empenha em sua profissão e a ela se dedica depende do contexto constituído pela forma global de sua vida. Ora, quando inicia sua vida de adulto, ela não tem atrás de si o mesmo passado de um rapaz; não é considerada de maneira idêntica pela sociedade; o universo apresenta-se a ela numa perspectiva diferente. $\mathrm{O}$ fato de ser uma mulher coloca hoje problemas singulares perante um ser humano autônomo (1967, p. 451-452).
\end{abstract}

Fazendo um paralelo desta afirmação com a obra Um teto todo seu, de Virginia Woolf, percebemos que as mulheres não conseguem se libertar totalmente das suas condições de subjugadas apenas tendo sua liberdade econômica e um lugar para dedicar-se à literatura. A sua produção literária será influenciada, também, pela sua condição de mulher numa sociedade em que predominam os valores instituídos pelo patriarcado.

Elaine Showalter também foi de suma importância para a formulação de uma crítica literária feminista. Na obra A Literature of Their Own, de 1977, ela classifica a literatura de autoria feminina em três fases, com base na literatura inglesa: feminina, feminista e fêmea:

Primeiro, há uma prolongada fase de imitação dos modos prevalecentes da tradição dominante, e internalização de seus padrões artísticos e visões sobre os papeis sociais. Em segundo, há uma fase de protesto contra estes padrões e valores, e a defesa dos direitos e valores das minorias, incluindo a demanda por autonomia. Finalmente, há uma fase de autodescoberta, um voltar-se para seu interior, livre de certas dependências da oposição, uma busca por identidade. Uma terminologia apropriada para as escritoras é chamar essas fases de Feminina, Feminista e Fêmea. (SHOWALTER, 2014, p. 11, tradução nossa).

A fase feminina compreende obras produzida no período entre 1840 e 1880 e caracteriza-se pela imitação dos padrões culturais dominantes. O patriarcado, então, era comumente apresentado como um modelo social natural nas obras dessa fase. Um exemplo é o romance Jane Eyre, de Charlotte Brontë, que acaba repetindo uma relação de gênero típica de uma sociedade patriarcal. Já a fase feminista vai de 1880 a 1920 e é caracterizada pelo protesto contra o modelo de opressão do patriarcado. Mrs. Dalloway (1925), de Virgínia Woolf, é um exemplo de literatura feminista. Nesse romance, o leitor se aproxima da condição de opressão da mulher naquele modelo social através do fluxo de consciência. A fase fêmea começa na década 1920 e se estende até a atualidade. Essa fase é marcada pela autodescoberta, visto que, 
durante as fases anteriores, a literatura de autoria feminina esteve ligada ao patriarcado, seja reproduzindo esse modelo social, ou lutando contra ele. Então, essa literatura produzida na contemporaneidade tenta constituir-se como uma literatura produzida pelo sexo feminino e para ele, em uma perspectiva identitária que se afasta da relação existente entre feminino e masculino como oposição biológica (SHOWALTER, 2014). Segundo Zolin (2003b), essas categorizações não podem ser consideradas absolutamente rígidas, pois é possível encontrar todas elas na obra de uma mesma escritora, ou ainda em uma mesma obra sobre uma mesma protagonista, já que as personagens oscilavam em termos de passividade, rebeldia, autoconhecimento, da mesma forma que havia oscilação nas lutas por direitos das mulheres em diversos setores sociais.

Com base nestas discussões, evidencia-se que a teoria feminista adentra no ramo literário e proporciona o surgimento de uma crítica literária feminista e, assim, esta tem a função de criticar a posição da mulher nas obras literárias, além de entender e proporcionar a evolução da autoria feminina. A literatura, então, no domínio do simbólico, apresenta espetos que podem representar o discurso que combate ou não a dominação masculina na sociedade. Assim, a crítica literária feminista vem expor como determinada obra literária apresenta essas simbolizações sociais, além de dar visibilidade à escrita de autoria feminina, que, por muito tempo, foi inferiorizada por críticos masculinos.

\section{As personagens Olanna e Kainene sob o olhar do feminismo}

Chimamanda Ngozie Adichie, autora de Meio Sol amarelo, nasceu em Enugu, Nigéria, em 1977. Escreve romances, contos e crítica feminista. Em Sejamos todos Feministas, publicado em 2014, a autora descreve como acontece a opressão do gênero feminino na Nigéria, apresentando como todos têm responsabilidades no engajamento para mudar a situação da opressão feminina. O fato de uma mulher nigeriana estar falando sobre sua realidade local demonstra uma certa independência dos conhecimentos ocidentais, pois ela leva em consideração a opressão que as mulheres nigerianas sofrem. Essa prática demonstra que as mulheres de países africanos tem o direto de mostrar ao mundo como elas percebem a desigualdade de gênero em suas realidades. Adichie exerce esse papel de transformação pelo discurso praticado através de sua condição de mulher nigeriana. (FREITAS, 2018).

No Brasil, ela é cada vez mais lida e sua literatura dialoga com temas que afetam diretamente a sociedade brasileira, como a questão da identidade negra feminina, muitas vezes invisibilizada, silenciada, como analisa Djamila Ribeiro, em Pequeno Manual Antirracista 
(2019). A crítica literária brasileira vê as obras dessa escritora numa perspectiva identitária, de raça e gênero no contexto do mundo globalizado:

Os romances de Adichie, no entanto, não se focam necessariamente na nação Nigeriana pós-colonial, mas também em experiências de sujeitos nigerianos, principalmente mulheres nigerianas, em um mundo global e transnacional, moldado pela imigração, por questões de raça, relações de gênero, amor e a ocidentalização imposta pelo neocolonialismo, onde as personagens lutam para criar suas próprias identidades sem se limitar pelas definições ocidentais. (ALVES e MENDES, 2019, p. 6)

Meio Sol Amarelo é um exemplo de como essa autora escreve atrelada às causas feministas, culturais e políticas da Nigéria e, de um modo geral, do povo africano. Esse livro foi o segundo romance publicado por Chimamanda Ngozi Adichie. (RESENDE, 2013)

Meio Sol Amarelo narra a história de um grupo de pessoas que, com transformações muito intensas ocorrendo na Nigéria nos anos 60, tenta se adaptar e sobreviver àquela nova realidade. Ugwu, garoto do campo, é inserido em uma nova realidade quando vai para a cidade e tenta entender as coisas ao seu redor; Odenigbo, patrão de Ugwu, é um professor universitário que é a favor da Guerra de Biafra para a independência do povo Igbo; Olanna, filha de uma família rica, decide se desvencilhar dos planos dos pais de fazê-la se casar com alguém que beneficie a família nos negócios, e vai morar em Nsukka, com Odenigbo; sua irmã gêmea, Kainene, considerada feia em relação a ela, tem a função de cuidar dos negócios da família; Richard é um inglês que foi para a Nigéria com vontade de desbravar o território e escrever um livro, tenta se adaptar à nova realidade e se apaixona por Kainene. A obra apresenta focos narrativos distintos, que denotam a diferença da percepção da realidade de cada personagem em decorrência das posições sociais que ocupam. A narrativa nos apresenta diferentes visões sobre fatos socias e políticos, e as personagens femininas também são vistas por diferentes ângulos, o que simboliza uma sociedade não homogênea em relação à mulher na sociedade.

Olanna e Kainene sempre foram ricas, podendo estudar no melhor colégio da Nigéria e fazerem faculdade no exterior. Em uma conversa com Richard, Kainene fala sobre a educação que receberam: "A injustamente cara e enigmática escola secundária britânica que minha irmã e eu fizemos. Meu pai achava que éramos muito pequenas para sermos mandadas ao exterior, mas estava resolvido a ter duas filhas tão parecidas com as europeias quanto possível.” (ADICHIE, 2008, p.76). Essa passagem apresenta o avanço que as mulheres tiveram em relação à educação, mas apenas para as mulheres africanas que, em um país colonizado, tiveram acesso 
a um ensino de qualidade, o que evidencia a desigualdade social presente naquela sociedade. $\mathrm{O}$ tipo de educação era o que tornava as mulheres Nigerianas em mulheres parecidas com as europeias, como enfatizou Kainene. Isso significa que as mulheres africanas só conseguiriam avançar em sua libertação do patriarcado através dos conhecimentos trazidos pelos brancos europeus. Elas estariam, de certa forma, atreladas aos conhecimentos advindos de uma cultura patriarcal e colonial, que as inferiorizam, as ensinavam a pensar e agir como mulheres brancas.

Olanna e Kainene, na condição de gêmeas não idênticas, evidenciam como essa diferença importa para a construção de sua personalidade. Kainene é considerada feia, então o pai lhe dá a função de tomar conta dos negócios da família, já Olanna, por ser considerada bonita, tem a função de se casar com um homem rico que trouxesse mais benefícios aos negócios. Em um jantar familiar, o ministro das Finanças, chefe Okonji, é convidado, e fica evidente a tentativa do pai em unir Olanna ao ministro, para receber certos benefícios políticos. Porém, Olanna não aceita uma proposta de trabalho oferecida: “"Eu decidi ir para Nsukka. Vou partir em duas semanas.' Ela viu a maneira como o pai comprimiu os lábios. A mãe deixou a mão suspensa no ar por alguns instantes, como se a notícia fosse trágica demais para que continuasse salpicando sal na comida" (ADICHIE, 2008, p. 42). Os pais se decepcionam, pois ela está indo contra os modelos tradicionais. A paralisia da mãe simboliza a percepção da tragédia que acabara de ocorrer: a filha não quer se casar com um marido escolhido pelos pais. A atitude de Olanna representa uma mulher vivendo em um contexto social que lhe permite essa tomada de decisão de forma natural. Já a mãe, por ser mais velha, carrega os valores sociais de um outro período histórico, em que o papel da mulher sempre foi o casamento para ascender socialmente. Na comparação entre as visões de mãe e filha, os valores que Olanna segue prevalecem, pois é mais fácil que uma mulher como ela, formada, com emprego, independente, não se submeta a um casamento por interesses familiares.

Olanna vai para Nsukka morar com o companheiro, porém estabilizada financeiramente, sem depender de uma figura masculina. Sua libertação, nesse sentido, parte dessa independência financeira, como afirmava Beauvoir (1967) ao dizer que uma mulher só se libertaria por meio do trabalho. Porém, é importante observar a categorização desta mulher. Uma mulher pobre e com um salário muito baixo pode trabalhar, mas, mesmo assim, continuar dependente de um homem, pois seu salário não poderia suprir todas suas necessidades. Portanto, o trabalho como forma de libertação está muito ligado às classes sociais. 
No mesmo jantar, vemos que Kainene se diferencia de sua irmã em relação ao tratamento recebido pela família e pelo ministro, que só repara na sua existência após perceber que Olanna não estava interessada nele: "Mas ele se virou e perguntou, com falsa vivacidade: 'E quanto a você, Kainene?"' (ADICHIE, 2008, p. 43). A beleza determina o tratamento de uma mulher, porém esta é uma construção social que muda de acordo com a cultura de um lugar ou de uma época, como discute Perrot (2007). Kainene, por exemplo, é uma mulher magra e alta e, por isso, é considerada feia, mas, para a cultura ocidental atual, uma mulher com essas características físicas é considerada bonita. A beleza é um padrão variável imposto às mulheres, causando inferiorização de uma parte delas, que não podem adequar-se a esses padrões.

O pai também a trata de forma diferente, pois dá a ela a função de cuidar dos negócios e fala com orgulho que ela representa dois filhos homens: "'Kainene não é só como um filho, ela é como dois filhos homens', disse o pai." (ADICHIE, 2008, p. 43). Essa fala está associada à cultura de famílias nigerianas que anseiam por filhos homens para carregarem o nome do pai, já que uma filha mulher formará outra família. Então, ter duas filhas mulheres é algo ruim naquela sociedade machista, por isso, ele sente a necessidade de compará-la a dois homens.

Em Kanno, povoado pobre em que Olanna foi visitar alguns familiares, ela conversa com a prima Arize sobre a relação dela com Odenigbo, e verifica-se como são diferentes as percepções sobre o casamento para as duas:

"Casar, propriamente, não. Eu só quero ficar perto dele, e também quero dar aula." [...]

"Só mulheres que têm todo esse estudo feito você podem dizer uma coisa dessas, irmã. Se as pessoas como eu, que não tem estudo, esperarem muito mais, vamos todos acabar extintos." (ADICHIE, 2008, p. 54)

A visão de Arize é daquela que precisa casar-se para suprir suas condições materiais de existência, e a ideia da maternidade é parte inerente a isso. Olanna não tem pressa em se casar, pois para ela o casamento não é prioridade, já que sua condição financeira lhe proporcionar segurança. O casamento, então, assume sentido diverso para mulheres de diferentes classes econômicas; isso, às vezes, não é perceptível à muitas mulheres, por isso, Arize se espanta ao ouvir que Olanna não pretende se casar com o companheiro. A visão de muitas mulheres é limitada devido às condições financeiras e educacionais precárias. Sem estudo e vivendo na pobreza, seu papel é de propagação dos valores patriarcas, pois essa é sua única realidade possível, o que nos remete ao que Woolf (1990) discute: uma mulher só consegue viver outra realidade se conseguir independência financeira. 
Olanna viaja a Londres para consultar-se com um ginecologista, e a mãe de Odenigbo o visita e conversa com Ugwu: "“Você sabe fazer ofe nsala bem?' 'Eu nunca fiz' 'Por quê? Meu filho gosta.' 'Minha patroa nunca pediu pra eu cozinhar isso."' (ADICHIE, 2008, p. 47). Nessa conversa, fica evidente que é de Olanna a responsabilidade sobre o cardápio da casa. Para a mãe, não cabia ao homem da casa decidir o que o empregado deveria cozinhar. É destinada à Olanna, então, a função de gerenciadora do lar, assumindo assim a vida interna, mas, ao mesmo tempo, sendo professora e tendo uma vida externa ao lar. Essa ideia de separação de funções, vida interna para a mulher e vida externa para o homem, advém dos ideais rousserianos, fortemente defendidos na Revolução Francesa (ALVES e PITANGUY, 1985). Porém, Olanna consegue habitar a vida externa, mas o ideal de que a vida interna é responsabilidade dela ainda continua, e a sogra, habituada a repetir padrões sexistas, tenta perpetuar a dominação masculina sobre a nora.

Adiante na narrativa, a traição de Odenigbo com a empregada que a mãe trouxera da aldeia, uma jovem chamada Amala, muda a dinâmica do casamento. Magoada, Olanna sai de casa, e acaba tendo uma relação sexual com Richard. Depois, o casal se entende, mas há uma espécie de regressão no patriarcado: "Eu nunca culpei Amala", disse ela. "Foi em você que eu depositei minha confiança, e a única maneira de alguém mexer com essa confiança era tendo sua permissão. [...] Você devia ficar bravo comigo, não com Richard", disse ela." (ADICHIE, 2008, p. 288). É apresentada no romance uma sequência de erros cometidos por Odenigbo: a traição, que resultou em uma gravidez, e a forma possessiva e enciumada como ele agiu após Olanna ter contado sobre a relação sexual que teve quando estava separada. Odenigbo a culpa, como se ela o tivesse traído, numa clara posição sexista, em que o homem pode trair a esposa, mas a esposa, nem mesmo separada, pode ter relações sexuais com outro homem.

A forma como aquela sociedade se organiza faz com que Olanna fique indecisa sobre o tipo de decisão a ser tomada em relação aos erros cometidos pelo companheiro; chega até a pedir conselho para o padre, que a exorta a voltar para o marido, representando o discurso religioso discutido por Perrot (2007), que é um mecanismo de dominação, como entendeu Bourdieu (2012). No perdão, temos a representação literária de uma ideologia patriarcal, em que a mulher acaba sendo retratada com estereótipos construídos socialmente, como aponta Millett (1970). Podemos entender essa representação literária como uma forma de criticar o fato de que a mulher não consegue a libertação de forma individual, o contexto político-social também precisa cooperar com o movimento feminista, senão, as mulheres, por conta de uma 
internalização dos valores patriarcais, não terão muitas escolhas a não ser seguir o mesmo caminho de Olanna.

Quando Amala teve o bebê, não quis ficar com a menina. Então, para resolver esse impasse, Olanna afirma: “Nós vamos ficar com ela', disse Olanna. Assustou a si própria com a clareza com que articulara o desejo de ficar com o bebê e de como lhe parecia a coisa certa a fazer." (ADICHIE, 2008. p. 293). Essa decisão, que pra ela parece tão clara, representa a manifestação da sua aceitação de mulher inferior, que não consegue engravidar. Conformada com isso, aceita criar uma criança fruto de uma traição do companheiro, porque isso traz um certo alívio para ela que já está farta do sofrimento causado pelos erros do marido e, também, pode cumprir seu papel de mãe, cobrança social que ela internaliza.

Após a eclosão da Guerra civil de Biafra, Olanna e a família se refugiaram na cidade de Humuahia, e ao mostrar a foto de sua irmã para uma professora, esta comenta:

"Ela estava fumando, naquela foto que você me mostrou. Feito uma prostituta comum." Olanna parou e olhou fixo para a professora. "Não estou dizendo que ela seja uma prostituta", disse ela mais que depressa. "Estou só dizendo que não é bom que ela fume porque mulheres que fumam são prostitutas." (ADICHIE, 2008, p. 317)

Kainene é julgada como imoral, algo recorrente na narrativa. Essa personagem, por se afastar de um perfil de mulher socialmente aceita naquela sociedade, acaba sempre analisada com um olhar preconceituoso. Neste caso, uma professora faz esse julgamento à Kainene, um agravante ainda maior, pois percebe-se que a educação oferecida para as crianças naquele país parte de pessoas que carregam de forma muito clara essa moral com base no patriarcado. Como esclarece Wollstonecraft (2016), as mulheres precisam de uma educação que valorize o intelecto, para que elas possam se libertar de uma naturalização da condição de inferioridade. A professora está tão presa a essa moral que nem percebe que seu julgamento inferioriza seu próprio gênero e, provavelmente, ao lecionar, irá transmitir esses valores para as crianças, sendo um sujeito ativo na manutenção da ideologia patriarcal, como aponta Bourdieu (2012).

O romance finaliza sem deixar claro o fim de Kainene, que sumiu misteriosamente ao tentar negociar alimentos na área inimiga, e Olanna não perde as esperanças de encontra-la. As duas, ao logo da narrativa, se diferenciam em praticamente tudo. Embora Olanna tenha desafiado a ordem familiar e se casado com o homem escolhido por si, um evolucionário, e tenha decidido se dedicar à carreira de professora, como queria, ela também cede às imposições patriarcais, aceitando a traição do marido, submetendo-se à maternidade para se sentir 
completa. Já Kainene, embora tenha seguido os passos do pai nos negócios e cuidado da empresa familiar, só o fez por conta da sua condição de mulher considerada feia, que não poderia ser usada como chamariz a maridos ricos. Teve que enfrentar a sociedade desde cedo, o que lhe garantiu uma autonomia maior, a ponto de se relacionar com um homem branco estrangeiro sem ser usada ou diminuída. Se tornou uma mulher de negócios e teve mais liberdade, porém com sequelas psicológicas por se sentir a filha feia.

\section{Conclusões}

A análise do romance Meio sol amarelo, com base na crítica literária feminista, revelou que as irmãs gêmeas, Olanna e Kainene, avançaram contra o patriarcado. Ambas, por conta de suas condições financeiras elevadas, usufruem de diversas conquistas do feminismo: estudar, entrar em uma universidade, conseguir independência financeira, etc. Porém, quando analisamos o contexto social da Nigéria, evidenciamos que as conquistas das imãs não se estendem à maioria das outras personagens femininas, que são de classes sociais inferiores, o que indicou que o avanço no patriarcado está ligado a fatores econômicos. Entretanto, há também recuo em relação à libertação feminina, pois a sociedade da época estabelece certas barreiras socias que impedem um avanço maior.

Olanna cede mais às imposições do patriarcado em comparação à irmã. Por ter certos privilégios sociais e conseguir se adequar aos padrões estéticos exigidos pela sociedade da época, ela sofre menos, mas, aceita a determinação de uma condição de inferioridade perante a um homem; seu desejo de ser mãe apresenta-se como uma imposição patriarcal, ao qual ela cede e cria uma filha fruto da traição do marido para sentir-se uma mulher completa e se torna dependente financeiramente do companheiro durante a guerra de Biafra.

Kainene consegue romper mais com as imposições patriarcais, porque possui uma condição de privilégio, como já apontamos, mas, também, pelo fato de ser considerada feia, o que lhe causou um tratamento diferenciado, acarretando-lhe consequências psicológicas. Como seu pai lhe deu a função de cuidar dos negócios, essa personagem teve a oportunidade de se desenvolver na área financeira, então, se tornou uma mulher mais autônoma e independente; teve um relacionamento amoroso distinto dos modelos pré-estabelecidos e não estava ligada à vida interna, da casa, dos assuntos domésticos, como sua irmã. Porém, ela demonstra ser uma pessoa com conflitos internos. Em muitos momentos da narrativa, parece tentar se manter indiferente às situações em que recebe um determinado tratamento por conta da sua condição 
estética, mas acaba deixando escapar os sentimentos recalcados que indicam seu sofrimento por desse tratamento diferenciado. E, ainda, se mostra como uma pessoa que não conseguiu desenvolver plenamente seu lado afetivo, sendo incapaz de demonstrar afeto, por exemplo.

Esses avanços das personagens provam que os movimentos feministas conseguiram conquistas significativas para o gênero feminino, visto que direitos como educação, trabalho externo e a autonomia na vida amorosa foram conquistados através de lutas, podendo agora ser representados na literatura como uma característica verossímil.

A Guerra de Biafra também foi um fator significativo para a mudança na posição social dessas personagens. As irmãs foram obrigadas a descer de classe social, por serem ibos e terem que se exilar. Nessas condições precárias, o comportamento dos personagens se alterou. Olanna sofre com um marido que lhe trata de forma diferente e Kainene, devido às condições, tenta se reinventar e consegue lucrar com a guerra. Ambas sofrem devido à crise, porém Kainene sente menos esse impacto, já que ela parece ter mais autonomia do que a irmã, pois sempre teve que sobreviver às condições sociais difíceis para seu tipo de mulher, além disso, ela não segue nenhum marido, como Olanna o fez.

\section{Referências bibliográficas}

ADICHIE, Chimamanda Ngozi. Meio Sol Amarelo. Tradução Beth Vieira. São Paulo: Companhia das Letras, 2008.

ADICHIE, Chimamanda Ngozi. Sejamos todos feministas. Tradução Christina Baum. São Paulo: Companhia das Letras, 2015.

ALVES, Ana Claudia Oliveira Neri; MENDES, Algemira de Macedo. Chimamanda Ngozi Adichie: Narrativas que rompem com as fronteiras da identidade. In: PEREIRA, Denise. (org.) Diversidade: diferentes, não desiguais. Ponta Grossa: Atena Editora, 2019. (Ebook). p. 1-13. ALVES, Branca Moreira; PITANGUY, Jacqueline. O que é feminismo. São Paulo: Brasiliense, 1985.

BEAUVOIR, Simone de. O Segundo sexo: Fatos e mitos. Tradução de Sérgio Milliet. Rio de Janeiro: Nova Fronteira, 1970.

BEAUVOIR, Simone de. O Segundo sexo: a experiência vivida. Tradução de Sérgio Milliet. Rio de Janeiro: Nova Fronteira, 1967.

BONNICI, Thomas. Teoria e crítica literária feminista: conceitos e tendências. Maringá: Eduem, 2007. 
BOURDIEU, Pierre. A dominação masculina. Trad. Maria Helena Hühner. 11ª . Ed. Rio de Janeiro: Bertrand Brasil, 2012.

FREITAS, Alessandra Martich. Feminismo africano e nigeriano em Americanah de Chimamanda Ngozi Adichie: da teoria à ficção. Anais do COPENE. Minas Gerais, 2018. PDF. RIBEIRO, Djamila. Pequeno manual antirracista. 1.ed. São Paulo: Companhia das Letras, 2019.

MILlETT, Kate. Política Sexual. Trad. Alice Sampaio, Gisela da Conceição e Manuela Torres. Lisboa: Publicações Dom Quixote, 1970.

MICHEL, Andrée. O Feminismo: Uma abordagem histórica. Rio de Janeiro: Zahar, 1982.

PERROT, M. Minha história das mulheres. Trad. Ângela M. S. Côrrea. São Paulo: Contexto, 2007.

RESENDE, Roberta Mara. Gênero e Nação na ficção de Chimamanda Ngozi Adichie. (Dissertação de mestrado) Programa de Mestrado em Letras da Universidade Federal de São João del-Rei. Minas Gerais, 2013.

SHOWALTER, Elaine. A Literature of Their Own: British Women novelists from Brontë to Lessing. New Jersey: Princeton Up, 2014.

WOLLSTONECRAFT, Mary. Reivindicação dos direitos da mulher. Tradução de Ivania Pocinho Motta. São Paulo: Boitempo, 2016.

WOOLF, Virginia. Um teto todo seu. Rio de Janeiro: Nova Fronteira, 1990.

ZOLIN, Lúcia Ozana. Crítica Feminista In: BONNICI, Thomas; ZOLIN, Lúcia Ozana. Teoria Literária: Abordagens históricas e tendências contemporâneas. Maringá: Eduem, 2003a, p. 161-183.

ZOLIN, Lúcia Ozana. Literatura de autoria feminina. In: BONNICI, Thomas; ZOLIN, Lúcia Ozana. Teoria Literária: Abordagens históricas e tendências contemporâneas. Maringá: Eduem, 2003b, p-253-261. 